\section{Good Governance and Development Mandate}

Dr Rituparna Bhattacharyya ${ }^{\dagger}$

Undoubtedly, the 16th Indian General (Lok Sabha) Election, 2014, is a sensational sweep for the Bharatiya Janata Party (BJP) winning 282 seats out of 543, tallying 339 with National Democratic Alliance (NDA). Indeed, this thumping win is a powerful proclamation for change at the Centre-a mandate of hope worth remembering in history, a debut for good governance and development. This was cascaded by two parallel waves:

- Anti-Congress wave directed against weak governance, food inflation, corruption and lack of job creation; and

- NaMO (Narendra Modi) wave based on 'Gujarat model of development'; these two semiotic waves delved deep into the subconscious minds of the Commons.

The ever-burgeoning debates on the glittering success and the buoyancy of the Gujarat model of development, also known as 'Modinomics', is based on the notion of 'open economy' with a staggering growth rate of $10 \%$ between the period 2004-2012 alongside increased reputation of being business-friendly, reduced red tapism and developed infrastructure-a home to many reputed industries of India - ship breaking yard, Reliance petroleum, gas-based thermal electricity generation and the most admired, Amul milk co-operative federation products. Besides, Gujarat is the largest producer of processed diamonds, wall clocks, castor and cumin. Further, Gujarat's impressive agricultural performance bears credibility.

The acceleration of economic growth of Gujarat stems from the new economic reforms of the 1990s which witnessed overall growth spurt across states but the geographical location of Gujarat with its close integration with the

\footnotetext{
${ }^{+}$Executive Editor, Journal Space and Culture, India; Alliance for Community Capacity Building in North East India, UK, Email: rituparna.bhattacharyya@accb.org.uk
}

global economies attributed to overall better performance when compared to many states, which gradually transformed the state into 'a powerhouse of growth'.

The buzzword 'development' is a multidimensional concept indicating a process of social and economic transformation. The dimensions of India's development are very complex and myriad; it spans from local and nuanced issues affecting individual states to poverty alleviation through to maintaining sustainable development to eradicating terrorism. In a similar context, George Soros of Open Society Foundations urged, "[d]evelopment targets should involve not just access to education, healthcare, clean water and other vital services, but also access to justice". In continuity with this, in his writing, he argues that the poor and the marginalised section with little or no access to resources are more frequently at peril of losing their homes or land upon which they rely upon for their everyday practices and financial support. Besides, they remain deprived of opportunity to gain access to the legal system; often refused justice due to rampant corruption and (mis)use of power. Hence, to deliver 'development' in real sense of the term, the component 'justice' must not only be added but also embellished to the notion of 'development'. In addition, people's active participation is necessary to contribute to a nation's development. That is, every citizen in their own capacity should forward their helping hand in nation building.

Notwithstanding, analysis of many development indicators indicate that 'Modinomics' is much more of a 'hype' than a reality-that Gujarat is the fifth economy in terms of Gross Domestic Product (GDP) for the financial years 2001-02 to 2013-14, as released by the Planning Commission of India-the first four economies are respectively Maharashtra, Uttar Pradesh, Andhra Pradesh and Tamil Nadu. Recent research by Maitreesh Ghatak and Sanchari Roy unpacks that in terms of per capita income, Gujarat occupies the third 
position after Maharashtra and Haryana; while in terms of average annual growth rate of per capita income Gujarat tops the rank along with Bihar followed by Andhra Pradesh, Maharashtra and Tamil Nadu.

Tackling extreme poverty, the primacy accorded by the Government of India, remains a key goal. Based on mixed reference period, the poverty statistics retrieved from the Department of Planning Commission, India reveals that with 5.09 per cent people below poverty line, Goa is the least poverty state against the national average of 21.92 per cent and the state of Gujarat ranks 14th with 16.63 per cent people below poverty line.

According to the India: Human Development Report 2011, Gujarat occupies the 11th rank when it comes to Human Development Index (HDI) performance. Kerala and New Delhi occupies respectively the top two positions; the bottom two positions are occupied by Odisha and Chhattisgarh. Earlier in 2013, the outgoing United Liberation Alliance II (UPA II) set up Rahuram Rajan panel under the leadership of the former Economic Advisor, Raghuram Rajan, now Governor of Reserve Bank of India to probe the 'special category' status of the backward states. The panel developed a multidimensional index (MDI) and divided the 28 states into three categories: relatively developed, less developed and least developed depending on their respective MDI scores - the findings of the index places Goa and Kerala as the most advanced economies while Gujarat has been considered as 'less developed' and Odhisa and Bihar at the bottom of the ladder.

Good governance, development and growth are at the helm of the new NDA government. The hard reality is that even in the 21st century modern India, 600 million Indians defecate in open space; 130 million households fail to access drinking water and no cities of India receive piped water and electricity supply $24 \times 7$; and 160 million depend on firewood to cook their foods. The new government now aims to deliver these basic needs for every family by 2022. The honourable Prime Minister has been seen as a synonym of 'mofi'cation-a leader who could deliver on the aspirations of Indians; perhaps the 17th Lok Sabha election, 2019 would be a mandate on delivery, when the electorates greet him 'hello again' instead of bidding him 'bye bye'.

The articles of the first issue of the second volume of Space and Culture, India fall under the umbrella of 'development' dynamics. In their article, Suman Das and Dr Madhushree Das examine the relationship between income, migration and social adjustment of the 'Tripuri' tribe who migrated from the hills of Tripura to the urban and suburban centres for better living. Here, the authors try to probe the pattern of their living conditions and highlight the ways the Tripuris are trying to acclimatise in their new locality.

Dr Chandrama Goswami and Manisha Bhattacharyya delve deep to explore the rural labour market in Assam. They argue that although the Work Participation Rates (WPR) for males has increased during the period 1993-94 to 2009-10, but for females, it has been oscillating in between 15 to 20 per cent. With the rapid growth of population, there has been a parallel booming of Non-Farm Sector (NFS). At the same time, WPR of males in the farm sector has been decreasing in favour of the NFS. The unemployment rates for females are much higher when compared to their male counterparts in both the farm sector as well as the NFS. Gender equality remains paramount to inclusive growth. However, the farm sector of Assam has become saturated to create additional employment opportunities. Therefore, the authors advocate that the NFS of Assam, with its greater potential to generate employment, can both solve the unemployment problem and also contribute to the increased access of women to resources and employment opportunities.

Scheduled Caste (SC) population of India is one of the marginalised sections of India. In the said context, Dr Momita Goswami Barooah analyses the spatial pattern of literacy and its variations among the SCs of the Brahmaputra Valley, Assam, and urges that increase in literacy and 
education would uplift their socio-economic conditions.

In her attempt to hone her research skills, Priyanka Chakrabarty, a young scholar contemplates on Sultana's Dream, a Bengali science fiction. Written in 1905 by the radical Muslim feminist, Begum Rokeya Shekhawat, the work vehemently opposed the sociocultural and patriarchal practices of the then Muslim community. Sultana's dream is a short story, a feminist utopia depicting role reversals of males/females-framed in a place called Lady Land, the land is wholly run by women, whereas men remain confined in the jenana system. From the perspectives drawn from Sultana's dream, Ms Chakrabarty argues that the story has relevance in the contemporary times. She goes on to argue that over the years although there has been change in the status and role of Muslim women, however, Muslim women continue to remain deprived of on almost all socio-economic indicators when compared to women of other religious groups.

The current issue also publishes one book review-Jennifer Woods reviews the book titled Community Work: Theories, Experiences \& Challenges, edited by Kalpana Goel, Venkat Pulla and A.P. Francis, published by Niruta Publications, Bangalore, 2014. In addition, in our regular category of Publication Watch, we bring you information on some e-books from Taylor \& Francis group, journal articles and online resources-all available freely on the internet.

\section{Bibliography}

Baruah, A. (2014). The Prohibition of Employment as Manual Scavengers and their Rehabilitation Act, 2013: A Review, Journal Space and Culture, India, 1 (3), 9-16.

Bhattacharya, Prasanta and Borah, Rajashree (2014). Drinking Water in Guwahati City: Its Past, Present Status and Associated Problems, Journal Space and Culture, India, 1(3), 65-78.

Full Text: Pranab Mukherjee's speech at Lok Sabha joint session (2014 June 09). FirstPost Politics,
Retrieved

from:

http://www.firstpost.com/politics/full-text-

pranab-mukherjees-speech-at-lok-sabha-joint-

session-2-

1562443.html?utm_source $=$ ref_article.

Hashmi Sameer (2014 May 5). Can India's Economy Model Itself on Gujarat? BBC News Business, Retrieved from: http://www.bbc.co.uk/news/business27257790.

Ghatak, Maitreesh and Roy Sanchari (2014 March 23). Mirror, Mirror on the Wall, Which Is the Most Dynamic State of Them All? Ideas for India, Retrieved from: http://ideasforindia.in/article.aspx?article_id $=2$ 70\#sthash.kNHfNGOr.dpuf.

Gujarat Vittal Innovation City: A Hi-Tech Special Economic Zone Promoted by EMPI Vittal Centre Innopolis \& GIDC, Government of Gujarat, Retrieved from: http://gvic.in/web/index.php?page=whygujarat.

India-Human Development Report 2011: Towards Social Inclusion, Institute of Applied Manpower Research, Planning Commission, Government of India, Retrieved from: http://www.iamrindia.gov.in/ihdr_book.pdf.

Open-air Defecation of 600 Million Indians Targeted by Inventor, Sulabh International Social Service Organisation, Retrieved from: http://www.sulabhinternational.org/news/ope n-air-defecation-600-million-indians-targetedinventor.

Progress on Sanitation and Drinking Water2013 Update, World Health Organization and UNICEF, 2013, Retrieved from: http://apps.who.int/iris/bitstream/10665/8124 5/1/9789241505390_eng.pdf.

Raghuram Rajan Panel Tags Narendra Modi's Gujarat Economy as 'Less Developed' (2013 September 27). The Indian Express, Retrieved from:

http://archive.indianexpress.com/news/raghur am-rajan-panel-tags-narendra-modis-gujarateconomy-as-less-developed/1174586/0. 
Soros, George (2014, March). What Does Soros, George (2014, February 02). Justice Have to Do with Overcoming Poverty? Development's Missing Ingredient, Open Open Society Foundations, Retrieved from: Society Foundations, Retrieved from: http://www.opensocietyfoundations.org/explai http://www.opensocietyfoundations.org/voices ners/what-does-justice-have-do-overcoming/development-s-missing-ingredient. poverty. 